\title{
Trade liberalization and the Degree of Competition in International Duopoly ${ }^{1}$
}

\section{Damoun Ashournia, Per Svejstrup Hansen², Jonas Worm Hansen}

\author{
University of Southern Denmark \\ Department of Business and Economics \\ Campusvej 55, 5230 Odense M, Denmark
}

Version: August 31, 2008

The aim of this paper is to analyze how a reduction in trade costs influences the possibility for firms to engage in international cartels, and hence how trade liberalization affects the degree of competition. We consider an intra-industry trade model of the Brander and Krugman type but amended to allow for firms producing differentiated products. We have two main findings: The first is that trade liberalization may have an anti-competitive effect irrespective of the mode of competition. This contradicts conventional trade theory. The second is that there is no unique relation between a reduction in trade costs and the degree of competition. If firms compete in quantities and the degree of product differentiation is high, a lowering of trade costs would be pro-competitive if trade costs are initially high, but anti-competitive if trade costs initially are low. Hence, trade policy is not necessarily a substitute for competition policy.

Key Words: Trade liberalization, cartel stability, international duopoly, trade costs, product differentiation

Subject Classification: [JEL codes] F15, F12, L13

\section{INTRODUCTION}

Conventional trade theory suggests that trade liberalization - interpreted as a reduction in trade costs - will increase competition, since trade costs typically shelter the domestic market from foreign competition. Hence, lowering trade costs should increase competition by easing access to the domestic market. This conclusion is trivial in models of perfect competition but it needs to be considered more carefully once imperfect competition is present. In models of oligopoly with a homogenous product - or the simpler version of duopoly - intra-industry trade might emerge if trade costs are not too large as shown by Brander and Krugman (1983). But is also raises the possibility of collusion to emerge where firms maximize their joint profit by refraining from exporting to each other's market as shown by Pinto (1986). Hence competition is reduced. Clearly, such collusive or cartel behavior is not necessarily stable. If cartel stability is modelled as an infinitely repeated game, whether international cartels can be upheld or not depends critically on firms' discount factor that again depends on trade costs . There are two opposing forces at

\footnotetext{
${ }^{1}$ Helpful comments and suggestions from Philipp Schröder are gratefully acknowledged

${ }^{2}$ Corresponding author. e-mail: psh@sam.sdu.dk
} 
work: the lower the trade costs, the larger the incentive to break out of the cartel and export to the rival's market; on the other hand, when trade costs are lowered it is also easier for your rival to export to your market, and hence in the future punishment for breaking the cartel, your profit is lower. Which effect dominates depends on the market structure and analyses of this are the aim of our paper ${ }^{3}$

The aim of this paper is to analyze how a reduction in trade costs influences the possibility for firms to engage in international cartels, and hence how trade liberalization affects the degree of competition. We consider an intra-industry trade model of the Brander and Krugman type but amended to allow for firms producing differentiated products. By varying the degree of product differentiation we are able to analyze products ranging from "perfect complement" over independent products to perfect substitutes (a homogenous product), and we are therefore able to synthesize most of the existing literature into our model. We follow a well-established tradition when analyzing these types of models working with linear demand and constant marginal costs of production (see e.g. Pinto (1986), Fung (1991, 1992), Clarke and Collie (2003), Lommerud and Sørgaard (2001), Friberg and Ganslandt (2005), and Schröder (2007)). We find in contrast to much of the literature that there is no unique relation between a reduction in trade costs and the degree of competition, and this finding is independent of whether firms compete in prices or in quantities. The most striking results are obtained if firms compete in quantities, where the relationship is hump-shaped and depends on the degree of product differentiation. If firms compete in quantities and the degree of product differentiation is high, a lowering of trade costs would be pro-competitive if trade costs are initially high, but anti-competitive if trade costs initially are low. Hence, trade policy is not necessarily a substitute for competition policy.

There are a number of papers related to our paper. The one closest in spirit and in model setup is Lommerud and Sørgaard (2001). But in contrast to our paper they consider a homogenous good duopoly model of intra-industry trade, and it can therefore be seen as a special case of our paper. They show that if firms compete in quantities, a lowering of trade costs will always reduce the critical discount factor for collusion to be sustained, and hence trade liberalization is pro-competitive. If, on the other hand, firms compete in prices, trade liberalization is anti-competitive, and collusion is thus easier to sustain. The difference in the results between their paper and our paper lies in the fact that we allow for differentiated products. As demonstrated by Fung (1991), the joint profit maximizing solution (the cartel solution) is not necessarily each firm acting as a monopoly in its own market, when products are imperfect substitutes. In fact, the joint profit maximizing solution may involve intra-industry trade because consumers have love of variety. Hence, the relevant profit comparison, when considering breaking out of a cartel, is not between the discounted monopoly profit and the discounted profit of the Nash equilibrium, but between the discounted cartel profit with intra-industry trade and the discounted profit of the Nash equilibrium. Since intra-industry trade in the

\footnotetext{
${ }^{3}$ Some evidence of international collusive behaviour has been reported. Very recently (nov. 2007), The European Commission fined YKK, Prym, Coats and four other companies for, among other things, having shared markets and coordinated prices in the market for zip fasteners. Another example is the European cement industry where The European Commission in 1994 fined 42 cement producers for having secret cartel agreements aimed at limiting the sale of cement between EU member-countries. A third example concerns the synthetic fibre industry where Japanese and English producers had agreed not to export to each other's markets as disclosed by the Japanese antitrust authorities in 1972. In fact, there is a plethora of evidence for international cartel behavior.
} 
cartel solution is only viable if transport costs are not too high, we can obtain a difference in the results of our paper and Lommerud and Sørgaard (2001). The cartel solution is simply more attractive when transport costs are lower, and this makes is easier for the cartel to be sustained when transport costs are lowered from an initial low level.

As indicated above, Fung (1991) considers a model with differentiated products. His interest in that paper is to explain when intra-industry trade emerges as the cartel solution. He does not investigate the cartel stability issue. This is done in Fung (1992), but unlike our model he only considers competition in the domestic market and not competition both in the domestic and in the foreign market. A distinction we know from Brander and Krugman (1983) is essential. Another paper that deals with cartel stability in a Brander and Krugman type model is Pinto (1986). He considers a homogenous good duopoly and only quantity competition, and is as such much closer to Lommerud and Sørgaard (2001) than to our paper, though the results in Pinto (1986) turn out to be a special case in our paper.

Schröder (2007) has shown in a model with a homogeneous good similar to Lommerud and Sørgaard (2001), how cartel stability depends on the specification of trade costs. It turns out that the results from Lommerud and Sørgaard (2001) do not always carry over if trade costs are ad valorem instead of specific. The focus in our paper is on the degree of product differentiation and cartel stability, and not as much on the exact nature of trade costs. Therefore, we follow the tradition in this strand of literature and work with specific trade costs.

Papers that also consider a Brander and Krugman type model with differentiated products are Clarke and Collie (2003) and Friberg and Ganslandt (2005). They do, however, not study the issue of cartel stability but are alone focused on the welfare implications of trade in static games with Bertrand competition. We consider the welfare implications of our results to be beyond the scope of this paper but an interesting project for future research.

The paper is organized as follows. The next section introduces the model setup. Following that are the basic results under Cournot competition, which allow us to present the main results under Cournot competition in section 4. Section 5 presents the basic results under Bertrand competition allowing us to state the main results of Bertrand competition in section 6. The final section concludes.

\section{THE MODEL}

To analyze the impact of trade liberalization on the sustainability of collusion, we use a Brander and Krugman (1983) type model of intra-industry trade between two countries, 1 and 2. The only difference between the model of Brander and Krugman (1983) and our model is that we allow for products to be differentiated. There are two firms, where firm 1 is based in country 1 and firm 2 is based in country 2. It is assumed that the markets are segmented, so the decisions of the firms for the home market are independent of decisions for the foreign market. The firms produce with constant returns to scale, and there is a unit transportation cost $t$ associated with exporting. We assume that the demand structure is similar to the differentiated duopoly model by Dixit (1979), and hence we work with linear 
demand curves $^{4}$. The inverse demands are given by:

$$
\begin{aligned}
& p_{x_{i}}=\alpha_{1}-\beta_{1} x_{i}-\gamma y_{i} \\
& p_{y_{i}}=\alpha_{2}-\beta_{2} y_{i}-\gamma x_{i}
\end{aligned}
$$

where $i=1,2$ denotes country 1 and 2 , respectively. Firm 1 produces $x$, whereas firm 2 produces $y$. $\gamma$ represents the degree of product differentiation. If $0<\gamma<\beta_{j}$ goods are imperfect substitutes and as $\gamma \rightarrow \beta_{j}$, goods become perfect substitutes. If $-\beta_{j}<\gamma<0$ goods are imperfect complements, and as $\gamma \rightarrow-\beta_{j}$, goods become perfect complements. If $\gamma=0$ goods are independent of each other.

In order to show most clearly that it is the inclusion of differentiated products that accounts for our results, we work with complete symmetry between firms and countries. Hence, marginal costs are normalized to zero $c=0$ for both firms, and transportation costs are identical in the two countries $t_{1}=t_{2}=t$. For the sake of clarity and in accordance with existing literature, we simplify our model by choosing $\alpha_{1}=\alpha_{2}=1, \beta_{1}=\beta_{2}=1$. Hence, the inverse demand functions we work with are:

$$
\begin{aligned}
& p_{x_{i}}=1-x_{i}-\gamma y_{i} \\
& p_{y_{i}}=1-y_{i}-\gamma x_{i}
\end{aligned}
$$

and by inverting the inverse demand functions we obtain the direct demand functions:

$$
\begin{aligned}
& x_{i}=\frac{1-p_{x_{i}}-\gamma+\gamma p_{y_{i}}}{1-\gamma^{2}} \\
& y_{i}=\frac{1-p_{y_{i}}-\gamma+\gamma p_{x_{i}}}{1-\gamma^{2}}
\end{aligned}
$$

When firms compete in quantities (Cournot competition) we work with the inverse demand functions, and the direct demand functions when firms compete in prices (Bertrand competition).

Since we are interested in analyzing the conditions under which collusion can be sustained in a repeated game, we begin by stating the game that is played. The game is of the prisoner's dilemma type. Firms obtain a higher payoff (profit) if they collude and somehow share the markets. But each firm has an incentive to deviate and enter the foreign market, since that would entail a higher payoff. If ,however, the firm deviates from collusion, it will be punished in the future. We assume that the punishment is to revert to the Nash equilibrium forever, and hence firms play the grim trigger strategy ${ }^{5}$. The firm then has to weigh the short run gain from deviating with a lower payoff in the future. Whether collusion can be upheld or not depends on the firm's discount rate that again depends - among other things on the transport costs. These transport costs are the core of our analysis, since we try to answer how a change in the transportation cost affects the incentive for firms to collude. Trade liberalization is interpreted as a lowering of the unit transport cost, which has an ambiguous effect on the profits of the firms, as it may increase

\footnotetext{
${ }^{4}$ There is a well-establilshed tradition of working with linear demand curves in models of repeated games of the type we consider. Nevertheless, the assumption of linearity is still restrictive but generally not known to be a crucial simplification unless demand is very convex.

${ }^{5}$ Many possible punishment strategies can be considered. The aim of this paper is not to consider these different punishment strategies, so we work with the grim strategy.
} 
the short term gains from deviating, but can also make the subsequent punishment harsher. Trade liberalization can therefore be pro- or anti-competitive.

Firms can compete both in prices as well as in quantities. In the following, we will spend most effort on deriving the results when firms compete in quantities. The derivations under Bertrand competition are similar, and they will only be dealt with briefly.

\section{THE BASIC RESULTS - COURNOT COMPETITION}

The profits of the firms are given by:

$$
\begin{aligned}
& \pi_{1}=\pi_{1: 1}+\pi_{1: 2}=p_{x_{1}} x_{1}+\left(p_{x_{2}}-t\right) x_{2} \\
& \pi_{2}=\pi_{2: 1}+\pi_{2: 2}=\left(p_{y_{1}}-t\right) y_{1}+p_{y_{2}} y_{2}
\end{aligned}
$$

where the first subscript denotes the firm and the second the market. Since demand is symmetric between the two countries, it is sufficient to analyze the model from the viewpoint of one of the firms. In the following we analyze it from the viewpoint of firm 1.

Collusion can be sustained if the discounted value of all future collusive profits is equal to or greater than the sum of the one-shot deviation profits and the discounted value of all the future punishment profits. That is, the following expression must hold true:

$$
\begin{aligned}
\frac{1}{1-\delta} \pi_{1}^{C C} & \geq \pi_{1}^{C D}+\frac{\delta}{1-\delta} \pi_{1}^{C P} \Longrightarrow \\
\delta & \geq \delta^{*}=\frac{\pi_{1}^{C D}-\pi_{1}^{C C}}{\pi_{1}^{C D}-\pi_{1}^{C P}}
\end{aligned}
$$

where the first superscript denotes Cournot competition, and the second is $C$ : collusion, $D$ : deviation, and $P$ : punishment (Nash equilibrium). $\delta$ is the firms' discount rate. If $\delta$ is larger than some critical discount rate $\delta^{*}$, collusion can be sustained.

The profit in the Nash equilibrium is straightforward to calculate. Firm 1 maximizes its profit $\pi_{1}$ taking the output level of firm 2 as given. The resulting profit expressions for the markets in country 1 and 2 are:

$$
\begin{aligned}
& \pi_{1: 1}^{C P}=\frac{(2-\gamma(1-t))^{2}}{\left(4-\gamma^{2}\right)^{2}} \\
& \pi_{1: 2}^{C P}=\frac{(2-2 t-\gamma)^{2}}{\left(4-\gamma^{2}\right)^{2}}
\end{aligned}
$$

and the total profit on both markets is thus: $\pi_{1}^{C P}=\pi_{1: 1}^{C P}+\pi_{1: 2}^{C P}$. We note that for export to the competing market to be profitable, the resulting exporting quantity of firm 1 to market 2 should be positive. This requires that:

$$
t \leq \bar{t}^{C P}=\frac{2-\gamma}{2}
$$

where $\bar{t}^{C P}$ is the prohibitive level of transport under Cournot competition in the punishment phase. 
If goods are perfect substitutes, collusion simply means that each firm is a monopolist in its own market. Since exporting involves a transport cost, there is no reason to transport the exact same good to another country. This is, however not the case, when goods are imperfect substitutes or complements as shown by Fung (1991). Precisely because goods are imperfect substitutes or complements, it might be beneficial for firms to actually trade during collusion. The so-called collusive trade. Collusive trade will only emerge if transport costs are not too high. This possibility has to be taken into account and will together with the differentiated goods contribute to the novel results compared to e.g. Lommerud \& Sørgaard (2001).

Firms will trade during collusion if

$$
\pi_{1}^{C T} \geq \pi_{1}^{C M}
$$

where $\pi_{1}^{C T}$ denotes the profit the firm obtains under collusive trade in Cournot competition, whereas $\pi_{1}^{C M}$ is the monopoly profit.

During collusive trade, firms maximize their joint profits $\pi_{1}+\pi_{2}$. This gives us the collusive trade quantity, price and profit of firm 1:

$$
\begin{array}{lccc}
x_{1}=\frac{1-\gamma(1-t)}{2\left(1-\gamma^{2}\right)} & p_{x_{1}}=\frac{1}{2} & \pi_{11}^{C T}=\frac{1-\gamma(1-t)}{4\left(1-\gamma^{2}\right)} \\
x_{2}=\frac{1-t-\gamma}{2\left(1-\gamma^{2}\right)} & p_{x 2}=\frac{1+t}{2} & \pi_{12}^{C T}=\frac{(t-1)(t+\gamma-1)}{4\left(1-\gamma^{2}\right)}
\end{array}
$$

where the first line is the home market expressions of firm 1, and the second line gives us the foreign market expressions for firm 1 . The total collusion profits of firm 1 are the sum of the home market profit and the foreign market profit: $\pi_{1}^{C T}=$ $\pi_{11}^{C T}+\pi_{12}^{C T}$. If firms share the market by not exporting to each other, firms have a monopoly in their own market, and we obtain the monopoly quantity, price and profit of firm 1 (corresponds to $\gamma=0$ in the above equation, and $x_{2}=0$ ) where the superscript $M$ denotes monopoly:

$$
x_{1}=\frac{1}{2} \quad p_{x_{1}}=\frac{1}{2} \quad \pi_{1: 1}^{C M}=\frac{1}{4}
$$

By comparing the two profit expressions $\pi_{11}^{C M}$ and $\pi_{1}^{C T}$ we can find the level of transport costs $t_{s}$ that makes collusive trade viable. This gives us

$$
t \leq t_{s}=1-\gamma
$$

That is, if transport costs are not too high, firms trade during collusion, which is also what is found in Fung (1991).

When finding the deviation profits, we assume that the deviating firm takes the rival's output as given. That is, the rival is sluggish to react and first reacts in the next period. In the period of deviation the rival produces either the monopoly quantity or the collusive trade quantity depending on the setting firms are in. The resulting expressions regarding quantity, price and profit for firm 1 in the monopoly setting $\left(t>t_{s}\right)$ are:

$$
\begin{array}{llll}
x_{1} & =\frac{1}{2} & p_{x_{1}}=\frac{1}{2} & \pi_{1: 1}^{C D M}=\frac{1}{4} \\
x_{2}=\frac{2-2 t-\gamma}{4} & p_{x_{2}}=\frac{2+2 t-\gamma}{4} & \pi_{1: 2}^{C D M}=\frac{(2-2 t-\gamma)^{2}}{16}
\end{array}
$$


The total deviation profits for firm 1 are the sum of the profit of market 1 and market 2, respectively, $\pi_{1}^{C D M}=\pi_{11}^{C D M}+\pi_{12}^{C D M}$. Superscripts denote Cournot, and deviation or monopoly setting respectively.

When firms are in a collusive trade setting $\left(t \leq t_{s}\right)$, firm 1 breaks the collusive agreement by maximizing its own profit. Firm 2 is assumed to be sluggish in adjusting its quantity, and it therefore still produces the collusive quantities. Since demand is symmetric, we know from (13) and (14) that firm 2 produces $y_{2}=$ $\frac{1-\gamma(1-t)}{2\left(1-\gamma^{2}\right)}$ for its home market (market 2) and $y_{1}=\frac{(1-t-\gamma)}{2\left(1-\gamma^{2}\right)}$ for its foreign market (market 1). This gives us the deviation quantities, prices and profits of firm 1:

$$
\begin{aligned}
x_{1} & =\frac{2-\gamma(1-t)-\gamma^{2}}{4\left(1-\gamma^{2}\right)} \quad p_{x_{1}}=\frac{2-\gamma(1-t)-\gamma^{2}}{4\left(1-\gamma^{2}\right)} \\
\pi_{1: 1}^{C D T} & =\frac{\left(2-\gamma(1-t)-\gamma^{2}\right)^{2}}{16\left(1-\gamma^{2}\right)^{2}} \\
x_{2} & =\frac{2-2 t-\gamma-\gamma^{2}+t \gamma^{2}}{4\left(1-\gamma^{2}\right)} p_{x_{2}}=\frac{3 t \gamma^{2}+\gamma^{2}+\gamma-2 t-2}{4\left(1-\gamma^{2}\right)} \\
\pi_{1: 1}^{C D T} & =\frac{\left(\gamma^{2}+\gamma+2 t-t \gamma^{2}-2\right)^{2}}{16\left(1-\gamma^{2}\right)^{2}}
\end{aligned}
$$

where superscript $\mathrm{T}$ denotes the collusive trade setting. The total deviation profits for firm 1 are the sum of the profit of market 1 and market 2, respectively, $\pi_{1}^{C D T}=$ $\pi_{11}^{C D T}+\pi_{12}^{C D T}$.

\subsection{Collusion - Cournot Competition}

The monopoly setting $\mathbf{t}>\mathbf{t}_{s}=1-\gamma$

In the monopoly setting collusion can be sustained, if $\delta \geq \delta_{C M}^{*}=\frac{\pi_{1}^{C D M}-\pi_{1}^{C M}}{\pi_{1}^{C D M}-\pi_{1}^{C P}}$ where $\delta_{C M}^{*}$ is the critical discount rate when firms maximize their joint profits by being in monopoly and sharing the markets under Cournot competition. Substituting in the profit expressions from above, we get the following:

$$
\delta_{C M}^{*}=\frac{\left(\gamma^{2}-4\right)^{2}(\gamma+2 t-2)}{\gamma\left(\gamma^{4}+2 t \gamma^{3}-2 \gamma^{3}-4 \gamma^{2}-24 t \gamma+24 \gamma-32\right)}
$$

To find out how trade liberalization, interpreted as a reduction in trade costs, affects the critical discount factor in the monopoly setting, we obtain:

$$
\frac{\partial \delta_{C M}^{*}}{\partial t}=\frac{16(\gamma-2)^{3}(\gamma+2)^{3}}{\gamma\left(\gamma^{4}+2 t \gamma^{3}-2 \gamma^{3}-4 \gamma^{2}-24 t \gamma+24 \gamma-32\right)^{2}}
$$

The collusive trade setting $\mathbf{t} \leq \mathbf{t}_{s}=\mathbf{1}-\gamma$

In the collusive trade setting collusion can be sustained, if $\delta \geq \delta_{C T}^{*}=\frac{\pi_{1}^{C D T}-\pi_{1}^{C T}}{\pi_{1}^{C D T}-\pi_{1}^{C P}}$ where $\delta_{T}^{*}$ is the critical discount rate when firms trade and they maximize their joint profits under Cournot competition. By substituting the profit expressions from above we obtain $\delta_{C T}^{*}$ :

$$
\begin{aligned}
& \delta_{C T}^{*}=\frac{\left((\gamma-2)^{2}(\gamma+2)^{2}\left(2-2 t+t^{2}-4 \gamma+4 t \gamma+2 \gamma^{2}-2 t \gamma^{2}+t^{2} \gamma^{2}\right)\right)}{\left(64-64 t+32 t^{2}-128 \gamma+128 t \gamma+24 \gamma^{2}-24 t \gamma^{2}+12 t^{2} \gamma^{2}+88 \gamma^{3}\right.} \\
& \left.-88 t \gamma^{3}-54 \gamma^{4}+54 t \gamma^{4}-27 t^{2} \gamma^{4}+4 \gamma^{5}-4 t \gamma^{5}+2 \gamma^{6}-2 t \gamma^{6}+t^{2} \gamma^{6}\right)
\end{aligned}
$$


and the following partial derivative with respect to trade costs:

$$
\frac{\partial \delta_{C T}^{*}}{\partial t}=\frac{\left(8 t \gamma^{3}(2-t)\left(\gamma^{2}-4\right)^{2}\left(\gamma^{2}-1\right)^{2}\right)}{\left(64-64 t+32 t^{2}-128 \gamma+128 t \gamma+24 \gamma^{2}-24 t \gamma^{2}+12 t^{2} \gamma^{2}+88 \gamma^{3}\right.}
$$

\section{RESULTS - COURNOT COMPETITION}

With the above calculations we are now ready to state the main results.

Proposition 1. In a Cournot duopoly where products are imperfect substitutes $(0<\gamma<1)$, trade liberalization (a reduction in $t)$ :

i) will be anti-competitive if $0 \leq t \leq t_{s}=1-\gamma$

ii) will be pro-competitive if $t_{s}<t \leq \bar{t}^{C P}=\frac{2-\gamma}{2}$

Proof. First notice that when products are imperfect substitutes, that is $0<$ $\gamma<1$ we know that $\bar{t}^{C P}>t_{s}$. Hence, the range of transport costs that make collusive trade viable is strictly less than the range of transport costs that make deviation and subsequent punishment possible. Second, from (24) we observe that the denominator is always positive, and the numerator is positive when $0<\gamma<1$. Hence $\frac{\partial \delta_{C T}^{*}}{\partial t}>0$ and a reduction in $t$ reduces $\delta_{C T}^{*}$. The range of discount rates that makes collusion sustainable is therefore increased, and a reduction in $t$ is accordingly anti-competitive. Third, we know from (22) that the denominator is positive when $0<\gamma<1$, whereas the numerator is negative. Hence, $\frac{\partial \delta_{C M}^{*}}{\partial t}<0$, and the range of discount rates that make collusion sustainable is decreased, and a reduction in $t$ is thus pro-competitive. Furthermore, it is true that $\delta_{C T}^{*}\left(t=t_{s}\right)=\delta_{C M}^{*}\left(t=t_{s}\right)$, and also true that $\delta_{C M}^{*}\left(t=\bar{t}^{C P}\right)=0$.

Figure 1 illustrates the proposition

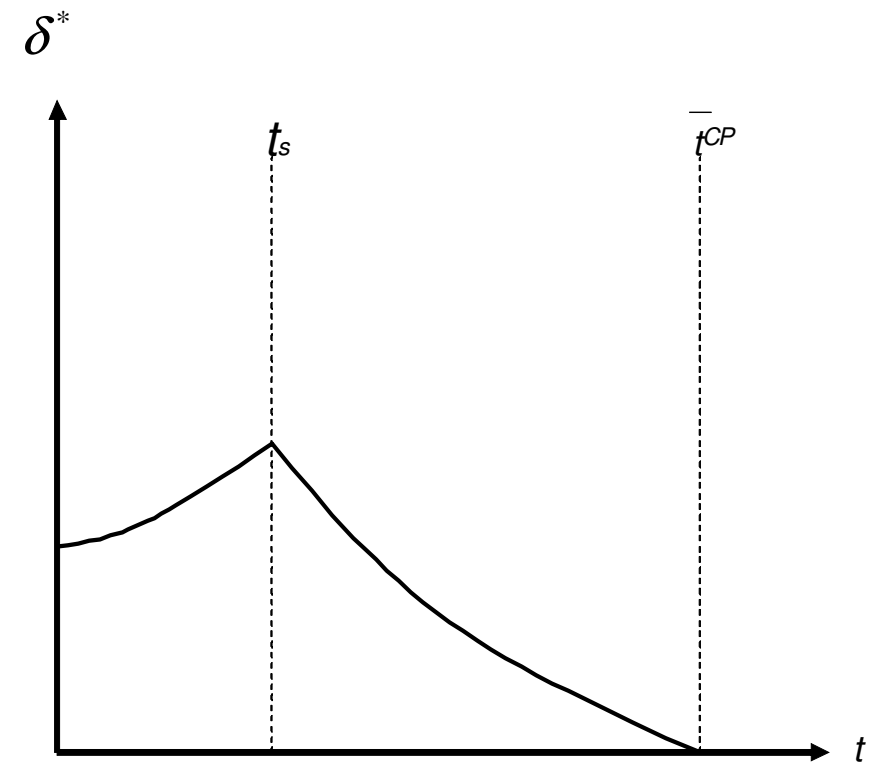

Fig 1: Critical discount rate in Cournot competition with imperfect substitutes 
Proposition 1 says that the effect of a trade liberalization is ambiguous when products are imperfect substitutes, and that the effect depends on the initial transport costs. If initially transport costs are sufficiently low such that firms trade during collusion, a lowering of the transport cost will reduce the incentive to deviate, and hence reduce competition. The intuition is straightforward: if it pays off to trade during collusion, reducing the costs to trade will obviously strengthen the collusive behavior. If, on the other hand, transport costs are initially so high that firms are in a monopoly setting during collusion, a lowering of trade costs will increase the incentive to deviate and export to the rival's market. Even though profit in the punishment phase decreases, the deviation profit increases numerically more.

As the degree of product differentiation increases, $t_{s}$ decreases, and the range of transport costs that make trade liberalization anti-competitive decreases. In the limit when $\gamma=1$ we are in the case with perfect substitutes, and our model reduces to Lommerud and Sørgaard (2001). In that case trade liberalization is always procompetitive, but as our model shows, this is by no means a general result; in fact it is only true in the limit.

Proposition 2. In a Cournot duopoly where products are imperfect complements $(-1<\gamma<0)$, trade liberalization (a reduction in $t$ ):

i) will be pro-competitive if $0 \leq t \leq \bar{t}^{C P}=\frac{2-\gamma}{2}$

ii) will have no effect on competition if $\bar{t}^{C P}<t \leq t_{s}=1-\gamma$

iii) will have no effect on competition if $t_{s}<t<\infty$

Proof. First notice that when products are imperfect complement, that is $-1<$ $\gamma<0$ we know that $\bar{t}^{C P}<t_{s}$. Hence, the relevant comparison with a deviation from joint profit maximization is to the collusive trade setting. If $\bar{t}^{C P}<t \leq t_{s}$ firms will never deviate from collusion, since transport costs are too high for firms to make positive profit in the punishment phase (the Nash equilibrium). Hence, firms will always collude and be in the collusive trade setting. If $t_{s}<t<\infty$ firms will always collude, and they will always be in the monopoly setting. Thus, in both case ii) and iii) firms will always collude, and a change in transport costs has no effect on competition. If $0 \leq t \leq \bar{t}^{C P}$ we know from (24) that the numerator is negative when $-1<\gamma<0$, because $(2-t)>0$ and $\gamma^{3}<0$. The denominator is always positive. Hence $\frac{\partial \delta_{C T}^{*}}{\partial t}<0$. A reduction of the transport costs therefore increases the critical discount factor, and trade liberalization is accordingly pro-competitive.

When goods are complements and transport costs are not too high such that firms trade during collusion $\left(0 \leq t \leq \bar{t}^{C P}\right)$, a lowering of trade costs will be procompetitive. That is, breaking out of collusion is more likely. The opposite of when goods are substitutes. The reason is that with Cournot competition and goods being substitutes, the choice variables are strategic substitutes. A firm can gain by exporting at the expense of the rival. When goods are complements, the choice variables are strategic complements, and the opposite is true. Both firms would benefit from increasing production. What prevents firms from increasing production and exporting are the transport costs. Hence a lowering of the transport costs would make breaking out of collusion more attractive. Thus, competition will be increased. 


\section{THE BASIC RESULTS - BERTRAND COMPETITION}

Under Bertrand competition, firms' choice variable is the price, and the relevant demand functions are therefore the direct demand functions given by (5) and (6). The results under Bertrand competition are derived in a similar way to the results under Cournot competition. The results will differ quantitatively but not in a qualitative way. Therefore, we will not go through the model under Bertrand competition in detail. Instead, we simply state the relevant profit expressions, and notice that the derivations follow lines akin to section 3 .

In the punishment phase (the Nash equilibrium) under Bertrand competition, the profit for the markets in country 1 and 2 are:

$$
\begin{aligned}
\pi_{1: 1}^{B P} & =\frac{(2-\gamma(1-t+\gamma))^{2}}{\left(1-\gamma^{2}\right)\left(4-\gamma^{2}\right)^{2}} \\
\pi_{1: 2}^{B P} & =\frac{(2-2 t-\gamma(1-\gamma t+\gamma))^{2}}{\left(1-\gamma^{2}\right)\left(4-\gamma^{2}\right)^{2}}
\end{aligned}
$$

where superscript B denotes Bertrand competition. The prohibitive transport cost is given by:

$$
\bar{t}^{B P}=\frac{\gamma(1+\gamma)-2}{\gamma^{2}-2}
$$

Hence, $t \leq \bar{t}^{B P}$ for export to take place in the Nash equilibrium.

When firms maximize their joint profit, it does not matter whether firms compete in prices or quantities. There is no strategic interaction. Hence, the relevant profit expressions are still given by (13), (14) and (15). This also implies, that the highest level of transport cost that just makes collusive trade viable is given by (16). That is $t \leq t_{s}$.

The deviation profit in the monopoly setting is:

$$
\begin{aligned}
& \pi_{1: 1}^{B D M}=\frac{1}{4} \\
& \pi_{1: 2}^{B D M}=\frac{(2-2 t-\gamma)^{2}}{\left(1-\gamma^{2}\right) 16}
\end{aligned}
$$

whereas deviation profit in the collusive trade setting is:

$$
\begin{aligned}
\pi_{1: 1}^{B D T} & =\frac{(2+\gamma(t-1))^{2}}{\left(1-\gamma^{2}\right) 16} \\
\pi_{1: 2}^{B D T} & =\frac{(2 t+\gamma-2)^{2}}{\left(1-\gamma^{2}\right) 16}
\end{aligned}
$$

Firms will only deviate if transport costs are not too high. Specifically, we require

$$
t \leq \bar{t}^{B D}=\frac{2-\gamma}{2}
$$

\subsection{Collusion - Bertrand Competition}

The monopoly setting $\mathbf{t}>\mathbf{t}_{s}=1-\gamma$

In the monopoly setting, collusion can be sustained if $\delta \geq \delta_{B M}^{*}=\frac{\pi_{1}^{B D M}-\pi_{1}^{B M}}{\pi_{1}^{B D M}-\pi_{1}^{B P}}$ where $\delta_{B M}^{*}$ is the critical discount rate, when firms maximize their joint profits by 
being in monopoly and sharing the markets under Bertrand competition. Substituting in the profit expressions from above, we get the following:

$$
\delta_{B M}^{*}=-\frac{\left(\gamma^{2}-4\right)^{2}(2 t+\gamma-2)^{2}}{\gamma\left(\begin{array}{c}
64 t+16 \gamma+12 t^{2} \gamma^{3}+32 t \gamma+32 \gamma^{2}+4 \gamma^{4} \\
+3 \gamma^{5}-32 t \gamma^{2}-16 t^{2} \gamma-24 t \gamma^{3}-4 t \gamma^{4}-64
\end{array}\right)}
$$

and

$$
\frac{\partial \delta_{B M}^{*}}{\partial t}=\frac{\left(8 t+4 \gamma+2 \gamma^{2}-\gamma^{3}+2 \gamma^{4}+\gamma^{5}-2 t \gamma^{2}-2 t \gamma^{4}-8\right)}{\gamma\left(\begin{array}{c}
12 t^{2} \gamma^{3}-16 t^{2} \gamma-4 t \gamma^{4}-24 t \gamma^{3}-32 t \gamma^{2}+32 t \gamma \\
+64 t+3 \gamma^{5}+4 \gamma^{4}+32 \gamma^{2}+16 \gamma-64
\end{array}\right)^{2}}
$$

The collusive trade setting $\mathbf{t} \leq \mathbf{t}_{s}=\mathbf{1}-\gamma$

In the collusive trade setting, collusion can be sustained if $\delta \geq \delta_{B T}^{*}=\frac{\pi_{1}^{B D T}-\pi_{1}^{B T}}{\pi_{1}^{B D T}-\pi_{1}^{B P}}$ where $\delta_{B T}^{*}$ is the critical discount rate, when firms trade when they maximize their joint profits under Bertrand competition. By substituting the profit expressions from above we obtain $\delta_{B T}^{*}$ :

$$
\begin{aligned}
& \delta_{B T}^{*}= \frac{\left(\gamma^{2}-4\right)^{2}\left(t^{2}-2 t+2\right)}{t^{2} \gamma^{4}-20 t^{2} \gamma^{2}+32 t^{2}-2 t \gamma^{4}+8 t \gamma^{3}} \\
&+40 t \gamma^{2}-64 t+2 \gamma^{4}-8 \gamma^{3}-40 \gamma^{2}+64
\end{aligned}
$$

and

$$
\frac{\partial \delta_{B T}^{*}}{\partial t}=\frac{8 t \gamma^{3}\left(\gamma^{2}-4\right)^{2}(t-2)}{\left(\begin{array}{c}
t^{2} \gamma^{4}-20 t^{2} \gamma^{2}+32 t^{2}-2 t \gamma^{4}+8 t \gamma^{3} \\
+40 t \gamma^{2}-64 t+2 \gamma^{4}-8 \gamma^{3}-40 \gamma^{2}+64
\end{array}\right)^{2}}
$$

\section{RESULTS - BERTRAND COMPETITION}

Proposition 3. In a Bertrand duopoly where products are imperfect substitutes $(0<\gamma<1)$, trade liberalization (a reduction in $t)$ :

i) will be pro-competitive if $0 \leq t \leq \bar{t}^{B P}=\frac{\gamma(1+\gamma)-2}{\gamma^{2}-2}$

ii) will have no effect on competition if $\bar{t}^{B P}<t \leq \bar{t}^{B D}=\frac{2-\gamma}{2}$

Proof. Note that when products are imperfect substitutes, $t_{s}<\bar{t}^{B P}<\bar{t}^{B D}$. Thus, the relevant constraints are $t_{s}$ and $\bar{t}^{B P}$ since transport costs higher than $\bar{t}^{B P}$ will not result in any deviation from collusion. When $t<t_{s}$ firms are in the collusive trade setting, and by inspection of $(36)$ we see that $\frac{\partial \delta_{B T}^{*}}{\partial t}<0$. This implies that a reduction in trade costs increases the critical discount rate, and hence collusion is more difficult to sustain. When $t_{s} \leq t \leq \bar{t}^{B P}$ firms are in the monopoly setting and inspection of (34) reveals that $\frac{\partial \delta_{B M}^{*}}{\partial t}<0$. A reduction of the trade costs increases the critical discount rate, and this has a pro-competitive effect. If $t>\bar{t}^{B P}$ firms will always collude and be in the monopoly setting.

When goods are imperfect substitutes, a lowering of the trade costs will have a pro-competitive effect unless trade costs are sufficiently high. If they are, it never 
pays off to deviate from monopoly. This result is in stark contrast to Lommerud and Sørgaard (2001) who found for the Bertrand case that, when good are perfect substitutes, trade liberalization will have an anti-competitive effect. To understand why the results from proposition 3 differ so markedly from Lommerud and Sørgaard (2001), let us take a look at what happens under Bertrand competition with perfect substitutes. In that case, a firm can capture the entire market by setting a price marginally lower than his competitor, because when the products are perfect substitutes, consumers only care about the price. Therefore, in the punishment phase, competition will be so harsh that there will only be one firm left to serve both markets, and the price will be competed approximately down to the transport costs. Even though firm 1 can capture the entire foreign market by deviating from collusion, it refrains from doing so because the future punishment is severe. Hence, Bertrand competition with perfect substitutes is a very harsh form of competition. When the products are imperfect substitutes, Bertrand competition is not nearly as harsh. Both firms will serve both markets during punishment, which increases the incentive to compete compared to the case with perfect substitutes. Since goods are substitutes and firms compete in prices, a deviating firm can gain a large market share, which also increases the incentive to deviate and compete. All in all, generally Bertrand competition with substitute goods will be pro-competitive unless goods happens to be completely homogenous.

Proposition 4. In a Bertrand duopoly where products are imperfect complements $(-1<\gamma<0)$, trade liberalization (a reduction in $t$ ):

i) will be anti-competitive if $0 \leq t \leq \bar{t}^{B D}=\frac{2-\gamma}{2}$

ii) will have no effect on competition if $\bar{t}^{B D}<t$

Proof. Note that when products are imperfect complements, $t_{s}>\bar{t}^{B P}>\bar{t}^{B D}$. If $t>\bar{t}^{B D}$ firms will never deviate from collusion; be it collusive trade or monopoly. Hence, a change in $t$ has no effect on the degree of competition. If $0 \leq t \leq \bar{t}^{B D}$ firms are in the collusive trade setting and a direct inspection of (36) reveals that $\frac{\partial \delta_{B T}^{*}}{\partial t}>0$. A reduction of transport costs therefore decreases the critical discount factor, and trade liberalization is anti-competitive.

In contrast to Bertrand competition with imperfect substitutes, a lowering of trade costs will be anti-competitive if goods are imperfect complements. The reason is that, when products are complements, is it beneficial for the firms to trade with each other, since it raises the demand for their products when both goods are traded on both markets. Since firms are already trading in collusion, a reduction of the trade costs makes it even more attractive to stay in collusion.

\section{CONCLUSIONS}

In this paper we have analyzed how a reduction in trade costs influences the possibility for firms to engage in international cartels, and hence how trade liberalization affects the degree of competition. By constructing an intra-industry trade model of the Brander and Krugman type consisting of two complementary settings, we have been able to analyze the effects of trade liberalization on the entire range of product differentiation for both price and quantity competition. We are therefore able to synthesize most of the existing literature into our model (Fung (1991), Fung (1992) and Lommerud and Sørgaard (2001) among others). 
We have two main findings that contradict conventional trade theory. The first is that trade liberalization may have an anti-competitive effect when goods are imperfect substitutes and firms are quantity setters. The second is that trade liberalization has an anti-competitive effect when goods are complements and firms are price setters. However, these results are also in contrast to the paper most closely related to ours - the paper by Lommerud and Sørgaard (2001). They consider a model where goods are homogenous (perfect substitutes) and find that under Bertrand competition, a lowering of trade costs will always be anti-competitive, whereas it will always be pro-competitive under Cournot competition. As our model shows this is indeed a limiting case. When goods are imperfect substitutes and firms compete in quantities, a reduction of trade costs is pro-competitive if trade costs are initially high, but anti-competitive if trade costs are initially low. If firms engage in price competition and goods are imperfect substitutes, a trade liberalization will most likely be pro-competitive and never anti-competitive as in Lommerud and Sørgaard. This shows just how restrictive the assumption of perfect substitutes can be.

When comparing the Cournot and Bertrand models, we see that the result of each model is approximately the opposite of the other model: with imperfect substitutes the Cournot model showed an anti-competitive effect while the Bertrand model was pro-competitive, and this was reversed with imperfect complements. The reason can partly be found with reference to Singh and Vives (1984) who demonstrated, that in a differentiated goods duopoly a game with Cournot competition where goods are substitutes, is qualitatively similar to a game with Bertrand competition where goods are complements; and a game with Cournot competition where goods are complements is qualitatively similar to a game with Bertrand competition where goods are substitutes. In the terminology of Bulow, Geneakoplos and Klemperer (1985), goods are strategic substitutes in the former kind of game, whereas they are strategic complements in the latter.

Schröder (2007) has shown that the results of Lommerud \& Sørgaard (2001) are not robust when considering other forms of trade costs such as ad valorem costs. This is a natural way of extending the results in our paper. It could also be interesting to extend our analysis by adopting other punishment paths, such as the maximum punishment, to see whether our results are robust in that aspect. We assume linear demand functions in constructing our model; it would therefore be interesting to know if this assumption is crucial for our results, or whether our results are more generally applicable. We have not considered the welfare implications of our results more generally, as this would be outside the scope of this paper.

This certainly shows that there are many prospects for future research in this field. Nevertheless, we still believe that the essence of our results will survive most possible extensions; namely that there is no clear-cut relation between industry structure, trade liberalizations and the degree of competition. 


\section{REFERENCES}

[1] Brander, James \& Paul Krugman, 1983, A 'Reciprocal Dumping' Model of International Trade, Journal of International Economics 15, pp. 313-321.

[2] Bulow, J., J. Geanakoplos and P. Klemperer, 1985, Multimarket Oligopoly: Strategic Substitutes and Complements, Journal of Political Economy, 93, 488-511.

[3] Clarke, R. and D. Collie, 2003, Product differentiation and the gains from trade under Bertrand duopoly, The Canadian Journal of Economics, vol. 36, no. $3,658-673$.

[4] Davidson, Carl, 1984, Cartel Stability And Tariff Policy, Journal of International Economics 17, pp. 219-237.

[5] Dixit, Avinash, 1979, A Model of Duopoly Suggesting a Theory of Entry Barriers, The Bell Journal of Economics, Vol. 10, No. 1, pp. 20-32.

[6] Friberg, R. and M. Ganslandt, 2005, Reciprocal dumping with Bertrand competition, SSE/EFI Working Paper Series in Economics and Finance, no. 592.

[7] Fung, K. C., 1991, Collusive Intra-Industry Trade, The Canadian Journal of Economics, Vol. 24, No. 2, pp. 391-404.

[8] Fung, K. C., 1992, Economic Integration as Competitive Discipline, International Economic Review, Vol. 33, No. 4, pp. 837-847.

[9] Lommerud, Kjell Erik \& Lars Sørgaard, 2001, Trade Liberalization and Cartel Stability, Review of International Economics, 9, pp. 345-355.

[10] Pinto, Brian, 1986, Repeated Games and the 'Reciprocal Dumping' Model of Trade, Journal of International Economics, 20, pp. 357-366.

[11] Schröder, Philipp J. H., 2007, Cartel Stability and Economic Integration, Review of International Economics, 15(2), pp. 313-320.

[12] Singh, N, and X. Vives, 1984, Price and Quantity Competition in a Differentiated Duopoly, Rand Journal of Economics, 15 (4), 546-554. 